\title{
Evaluation of the Mutation Profile via Next-Generation Sequencing in a Turkish Population with Non-small Cell Lung Cancer
}

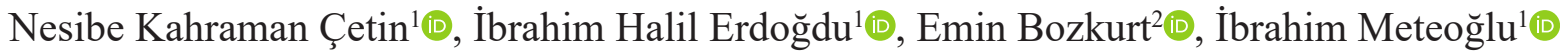 \\ 'Department of Pathology, Aydın Adnan Menderes University School of Medicine, Aydın, Turkey \\ ${ }^{2}$ Department of Veterinary, Eldivan Vocational School of Health Services, Çankırı Karatekin University, Çankırı, Turkey
}

Background: Lung cancer is the most common cancer type worldwide, with non-small cell lung cancer being the most frequently studied. Identifying of cancer-related genes in non-small cell lung cancer is crucial for developing individualized treatment, particularly as mutation profiles can vary by country and ethnicity.

Aims: To identify comprehensive mutation profiles in a cohort of Turkish patients with non-small cell lung cancer using the next-generation sequencing.

Study Design: Retrospective cross-sectional study.

Methods: In total, 72 cancer-related genes and 4149 variants were recorded in the non-small cell lung cancer panel, and their relationship with clinical and histopathological features was investigated through next-generation sequencing.

Results: Among 507 patients, 420 (82.8\%) were males and 87 (17.2\%)

were females. Percentages of phosphatidylinositol-4,5-bisphosphate 3-kinase catalytic subunit alpha (11\%), B-Raf proto-oncogene, serine/ threonine kinase $(8 \%)$, and neurofibromatosis type $1(6 \%)$ mutations were higher than those reported in the literature. Males had a higher rate of Kirsten rat sarcoma 2 viral oncogene homolog mutations $(P=.102)$, whereas epidermal growth factor receptor mutations were statistically more common in females $(P=.001)$. Multiple variants of strong significance were identified in $6.3 \%$ patients diagnosed with adenocarcinoma, most of whom were smokers. Kirsten rat sarcoma 2 viral oncogene homolog and phosphatidylinositol-4,5-bisphosphate 3-kinase catalytic subunit alpha mutations were most commonly observed.

Conclusion: This study shows that Turkish patients have higher rates of PIK3CA, BRAF and NF1 mutations compared to the literature. Studies to determine the molecular profile specific to Turkish people will guide clinicians in treatment and contribute significantly to determining priorities in diagnosis.

\section{INTRODUCTION}

Lung cancer, the most common type of malignancy in all societies, generally has a poor prognosis, and is the leading cause of cancerassociated mortality. ${ }^{1-3}$ Non-small cell lung cancer (NSCLC) is the most common subtype of lung cancer. It is generally diagnosed in advanced stages due to its silent clinical symptoms. ${ }^{4-7}$ Some patients benefit from surgery and various treatments; however, the success of treatment is still extremely low. ${ }^{8,9}$ For lung cancer, recent studies showing the distribution of the molecular profile have demonstrated their molecular heterogeneity., ${ }^{2,3}$ Characterization of NSCLC-specific genomic alterations is crucial to creating new, more successful treatment protocols specific to the patient and tumor type.
At present, most lung cancers are largely diagnosed by biopsy; however, molecular tests should also be performed using the most sensitive methods. ${ }^{2,10}$ Serial testing for different mutations is time-consuming and depletes limited tumor tissue. ${ }^{11}$ However, testing can be performed at many sites within many genes on a single platform using next-generation sequencing (NGS), providing a comprehensive mutational profile. ${ }^{11,12}$ In recent years, NGS technologies have become widespread, cost-effective, and more suitable for formalin-fixed paraffin-embedded (FFPE) tissues, making it easier to investigate mutations in lung cancers. ${ }^{8}, 13$ Thus, the multigene approach makes treatment protocols more efficient and provides economical use of limited tissue samples. ${ }^{11}$

Corresponding author: Nesibe Kahraman Çetin, Department of Pathology, Aydın Adnan Menderes University School of Medicine, Aydın, Turkey

e-mail: n.k.cetin@hotmail.com; nesibe.cetin@adu.edu.tr

Received: June 7, 2021 Accepted: September 10, 2021 Available Online Date: October 4, 2021 • DOI: 10.5152/balkanmedj.2021.21049

Available at www.balkanmedicaljournal.org

ORCID iDs of the authors: N.K.Ç. 0000-0002-4549-1670; İ.H.E. 0000-0002-3203-2301; E.B. 0000-0001-8963-631X; İ.M. 0000-0001-5367-0495.

Cite this article as:

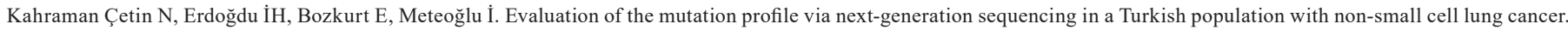
Balkan Med J. 2021; 38(6):382-391.

Copyright@Author(s) - Available online at http://balkanmedicaljournal.org/ 
The incidence and mutation profile of lung cancers vary across countries and ethnicities, and these changes can cause different responses to the same treatment. ${ }^{14-16}$ The mutation profile in NSCLC is complex due to the various characteristics of patients, mainly demographic and pathological. ${ }^{4,5}$ Determining the relationship between these characteristics and targetable mutations may help to develop and guide more effective treatment protocols. ${ }^{5}$ Therefore, a comprehensive database containing the genomic alterations of NSCLC patients is required for clinical interpretation of the mutations. ${ }^{4,10}$ At present, there are not enough studies on the frequency of mutations in lung cancer within the Turkish population. ${ }^{17-21}$ Treatment protocols are organized according to American and European data and guidelines. Obtaining data from Turkey is important to determining and implementing more successful diagnostic and treatment strategies in this country. Therefore, this study identified comprehensive mutation profiles in a large cohort of Turkish patients with NSCLC using NGS.
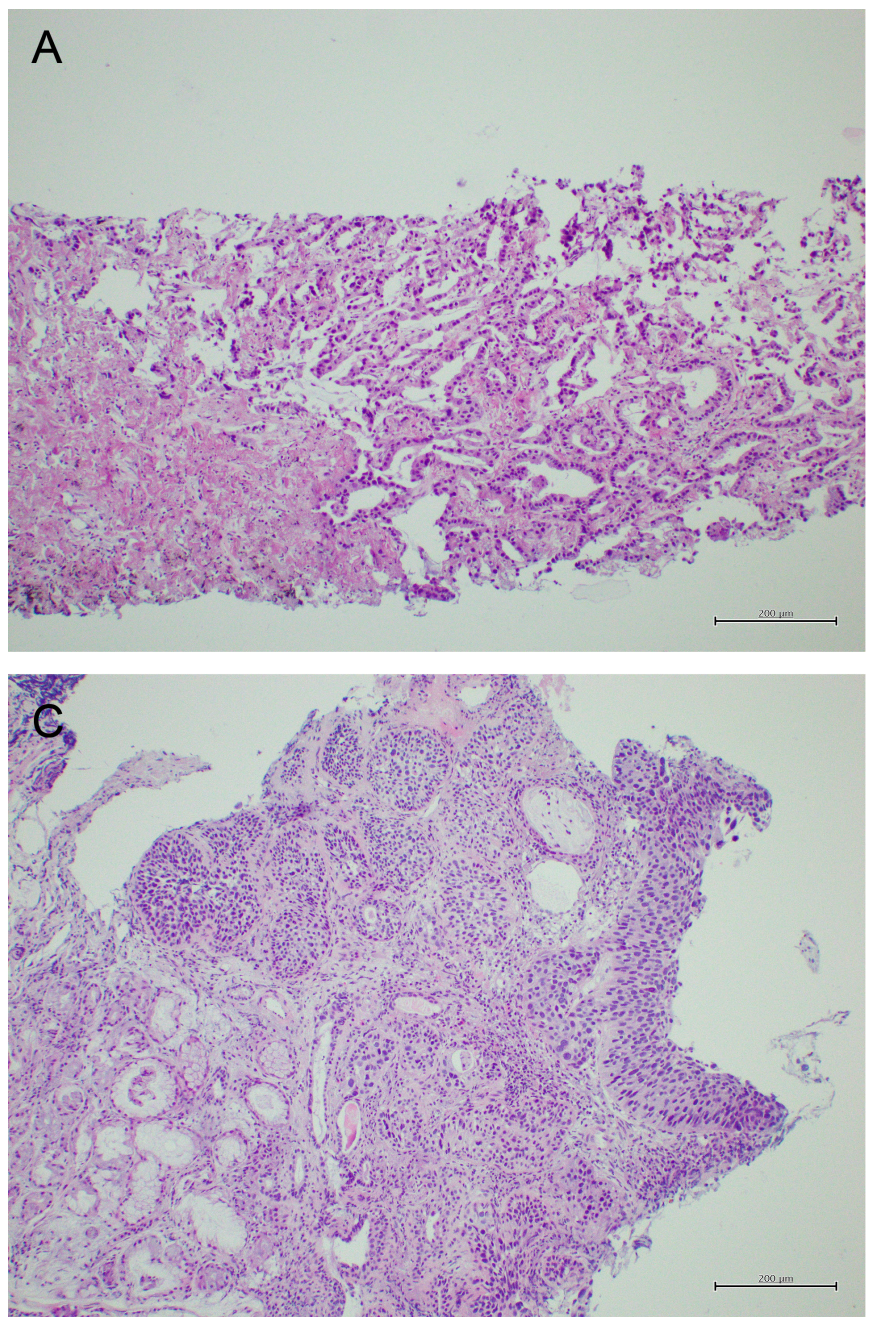

\section{MATERIAL AND METHODS}

\section{Patients}

This retrospective study included 507 histologically confirmed NSCLC patients who underwent molecular testing by NGS over 14 months (between November 1, 2018 and January 1, 2020). All patients from Aydin, its surrounding areas, and admitted from other regions of Turkey were of Turkish ethnic origin. Formalin-fixed paraffin-embedded tissue samples consisting of biopsy and resection materials were evaluated concomitantly with previous pathology reports and hematoxylin-eosin-stained sections (Figure 1). Data regarding patient clinical and histopathologic characteristics were obtained from pathology department records. A total of 72 cancer-related genes and 4149 variant analysis results from the lung cancer panel made by manufacturer of the NGS system were recorded (Table 1). Relationships between mutations and clinicopathological features were analyzed. Tumor cellularity was a primary exclusion criterion and the cut-off value was $5 \% .^{12}$

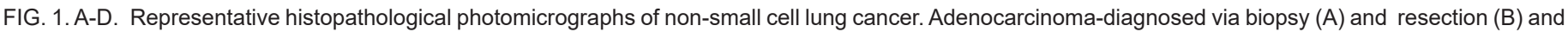
Squamous cell carcinoma diagnosed via biopsy (C), and resection (D) (100× magnification, hematoxylin-eosin staining). 
Formalin-fixed paraffin-embedded samples of 507 cases were successfully sequenced for subsequent variation analysis. All experiments were conducted at Aydın Adnan Menderes University Hospital, Pathology Laboratory, Molecular Pathology Unit.

\section{DNA Extraction from Formalin-Fixed Paraffin-Embedded Tissues}

Tumor areas were marked by pathologists, and genomic deoxyribonucleic acid (DNA) extraction was carried out from $10-\mu$ m-thick sections using the Qiagen FFPE DNA tissue extraction kit according to the manufacturer's instructions. Deoxyribonucleic acid was quantified using a Qubit fluorometer and Qubit 3.0 dsDNA HS assay kit (Life Technologies, Calif, USA). The study was continued with cases from which 100-150 ng of DNA was obtained.

\section{Next-Generation Sequencing Library Preparation and Sequencing}

This assay was performed with the QIAseq targeted Lung DNA panel (DHS-005Z, Qiagen, Strasse, Hilden, Germany; Table 1) with a MiniSEQ NGS platform (MiniSEQ, MN00676, Illumina, Singapore) with an optimized manufacturer's protocol. After DNA isolation from FFPE tissues, workflow continued with the following steps: target region enrichment, library preparation, clonal amplification, and NGS. Thereafter, 100-150 ng of FFPE DNA fragments underwent end repair. Target enrichment was amplified by polymerase chain reaction (PCR; Labcycler, Sensoquest GbmH, Göttinger, Germany). Then, barcoding and library preparation were performed. Libraries were amplified by PCR (Labcycler, Sensoquest) and purified for target enrichment. The target-enriched library was then sequenced using a MiniSEQ High Output Reagent Cartridge (Illumina, Inc., San Diego, Calif, USA) on MiniSEQ NGS platforms (MiniSEQ).

TABLE 1. Gene Content of Lung Cancer Panel (DHS-005Z-12 \& DHS-005Z-96)

\begin{tabular}{llll}
\hline AKT1 & FBXO7 & MGA & PTPRD \\
ALK & FBXW7 & MLH1 & RARB \\
AMER1 & FGFR1 & MUC16 & RASSF1 \\
APC & FGFR2 & MYC & RB1 \\
ARID1A & FGFR3 & NF1 & RBM10 \\
ATM & FHIT & NFE2L2 & RET \\
BAI3 & GRM8 & NOTCH1 & RIT1 \\
BAP1 & HRAS & NRAS & ROS1 \\
BRAF & JAK2 & NTRK1 & RUNX1T1 \\
CDKN2A & KDR & NTRK2 & SETD2 \\
CDKN2B & KEAP1 & NTRK3 & SMAD4 \\
CREBBP & KIT & PDGFRA & SMARCA4 \\
CTNNB1 & KMT2D & PIK3CA & SOX2 \\
DDR2 & KRAS & PIK3CG & SKT11 \\
EGFR & LRP1B & PIK3R1 & TNFAIP3 \\
EPHAS & MAP2K1 & PIK3R2 & TP53 \\
ERBB2 & MDM2 & PKHD1 & TSC1 \\
ERBB4 & MET & PTEN & U2AF1 \\
\hline
\end{tabular}

$B R A F, B$-Raf proto-oncogene, serine/threonine kinase; EGFR, epidermal growth factor receptor; KRAS, Kirsten rat sarcoma 2 viral oncogene homolog; $N F 1$, neurofibromatosis type 1; NRAS, neuroblastoma RAS viral oncogene homolog; PIK3CA, phosphatidylinositol -4,5-bisphosphate 3-kinase catalytic subunit alpha; TP53, tumor protein 53.

\section{Data Analysis}

Data analysis and quality control of array results were performed using the Qiagen Clinical Insight analysis universal commercial software. After examining the data quality, variants were transferred to the Qiagen Clinical Insight interpretation web interface which enabled data interpretation for predefined variants. Selected variants were analyzed using bioinformatics tools ((CADD(v1.3), Allele Frequency Community, EVS(ESP6500SIV2), Refseq gene model, JASPAR, Vista enhancer hg18, hg19, Clinical trials (Stepford 181112.001), PolyPhen-2, 1000 genome frequency(phase $3 v 5 b)$ ) to confirm the diagnosis and evaluate them according to their clinical impact and influence on the treatment protocols. Variations within patients were determined with Qiagen reporter and Qiagen Clinical Insight Browser platforms. A report was generated, comprised of a summary of findings per sample for each variable identified, followed by the Qiagen Knowledge Base with a direct link to the data source and listing the recommended treatment. The limit of detection for this panel was set as $5 \%$. The NGS testing process lasted approximately 5-7 days.

\section{Statistical Analysis}

All statistical analyses were conducted using SPSS version 22.0 software (IBM SPSS Corp; Armonk, NY, USA). Descriptive statistics and frequency analysis were used for determining frequency, mean, and standard deviation (SD). Comparisons between groups were performed using the $X^{2}$ test. A two-sided $P<.05$ was defined as significant for all analyses. The association between categorical variables was assessed using the $X^{2}$ test with Yates' $X^{2}$ approaches because the distribution of the minimum expected counts ranged between 5 and 25 values. Power analysis was performed based on the chi-square test. With an alpha $=0.05$ and effect size $(w)=0.14$, the power of the study was calculated as 0.813 . G*Power Version 3.1.9.2 statistical program was used for power analysis.

\section{RESULTS}

\section{Clinical and Histopathological Characteristics}

The mean age was 62.84 years (range, $25-90$ years, SD: 10.065). The study included $420(82.8 \%)$ males and 87 (17.2\%) females; the male:female ratio was 4.9 . The mean age of males was 63.14 years (26-88 years, SD: 9.39) and 61.40 years (25-90 years, SD: 12.82$)$ for females. Clinical and histopathological data are summarized in Table 2.

\section{Evaluation of the Mutation Profile by Next-Generation Sequencing}

Statistics for the 507 patients with NSCLC submitted for NGS have been reported. The customized targeted multiple gene panel contained cancer-related genes in which somatic mutations were prognostically important or predicted response to therapy. Variants detected in cancer-related genes in the NGS system were evaluated in 3 categories according to the AMP/ASCO/CAP (Association for Molecular Pathology/American Society of Clinical Oncology/College of American Pathologists) guidelines. ${ }^{22}$ In this study, variants of strong significance (VSS) (Tier 1A,1B) cancer-related genomic alterations in the database and the literature were assessed because validated predictive and prognostic variants were categorized. 
TABLE 2. Clinical and Histopathologic Characteristics of Patients

\begin{tabular}{|c|c|c|c|}
\hline \multirow[b]{2}{*}{ Variables and Category } & \multicolumn{2}{|c|}{ Gender } & \multirow[b]{2}{*}{ Total $(\%)$} \\
\hline & Male, n (\%) & Female, n (\%) & \\
\hline \multicolumn{4}{|l|}{ Age } \\
\hline Less than 30 years & $2(0.4)$ & $1(0.2)$ & $3(0.6)$ \\
\hline $30-39$ years & $2(0.4)$ & $2(0.4)$ & $4(0.8)$ \\
\hline $40-49$ years & $23(4.5)$ & $14(2.8)$ & $37(7.3)$ \\
\hline $50-59$ years & $108(21.3)$ & $23(4.5)$ & $131(25.8)$ \\
\hline $60-69$ years & $177(35)$ & $22(4.3)$ & $199(39.3)$ \\
\hline $70-79$ years & $95(18.7)$ & $20(4)$ & $115(22.7)$ \\
\hline More than 80 years & $13(2.5)$ & $5(1)$ & $18(3.5)$ \\
\hline \multicolumn{4}{|l|}{ Tumor Type } \\
\hline Adenocarcinoma & $354(69.6)$ & $77(15.4)$ & $431(85)$ \\
\hline Squamous cell carcinoma & $62(12.2)$ & $8(1.6)$ & $70(13.8)$ \\
\hline Adenosquamous carcinoma & $1(0.2)$ & $1(0.2)$ & $2(0.4)$ \\
\hline NSCLC & $3(0.6)$ & $1(0.2)$ & $4(0.8)$ \\
\hline \multicolumn{4}{|l|}{ Smoking status } \\
\hline Never smoker & $140(27.6)$ & $65(12.8)$ & $205(40.4)$ \\
\hline Former/current smoker & $280(55.2)$ & $22(4.4)$ & $302(59.6)$ \\
\hline Total (\%) & $420(82.8)$ & $87(17.2)$ & $507(100)$ \\
\hline
\end{tabular}

NSSCLC, non-small cell lung cancer.

Mutations were found in 19/72 cancer-related genes. A total of 296 of the 4149 variants in 19 genes were identified. Variants of strong significance were most commonly observed in Kirsten rat sarcoma 2 viral oncogene homolog $(K R A S)$ (41\%) followed by epidermal growth factor receptor $(E G F R)(18 \%)$, phosphatidylino sitol-4,5-bisphosphate 3-kinase catalytic subunit alpha (PIK3CA) $(11 \%)$, B-Raf proto-oncogene, serine/threonine kinase (BRAF) $(8 \%)$, and neurofibromatosis type 1 (NF1) (6\%, Figure 2). Kirsten rat sarcoma 2 viral oncogene homolog mutations were detected in $121 / 296$. When examining the spectrum of KRAS mutations, $92.5 \%(112 / 121)$ of VSS were in exon 2. Codon 12 represented $85.9 \%$ (104/121) of KRAS mutations. Mutations in other codons of $K R A S$ were largely represented by codons $13(6.6 \%, 8 / 121)$ and 61 (4.1\%, 5/121). Epidermal growth factor receptor mutations were detected in out of 53/296 variants using this assay. Exon 19 deletions $(64 \%, 34 / 53)$ were the most commonly observed mutations, followed by exon $21(22.6 \%, 12 / 53)$, exon $20(7.5 \%, 4 / 53)$, and exon $18(3.8 \%, 2 / 53)$. The most frequent PIK3CA mutations were detected in 33/296 variants and found on E545 (42.4\%, 14/33), Q546 $(6 \%, 2 / 33)$, and E542(3\%, 1/33) on the helical domain of exon 10, and H1047(27.2\%, 9/33) on the kinase domain of exon 21. Exon 10 contained 51.5\% (17/33) of VSS, and $33.5 \%$ $(11 / 33)$ were in exon 21 . In $B R A F, 60.8 \%(14 / 23)$ of VSS were in exon 15. p.V600E represented 39.1\% (9/23) of BRAF mutations. All VSS are listed in Table 3.

\section{Association of Patient Clinicopathological Characteristics with Variants of Strong Significance}

Considering the distribution of VSS by sex, KRAS (47.3\%), EGFR (11.5\%), PIK3CA (11.1\%), BRAF (8.4\%), and NF1 (6.2\%) mutations were most frequently observed in males, whereas EGFR

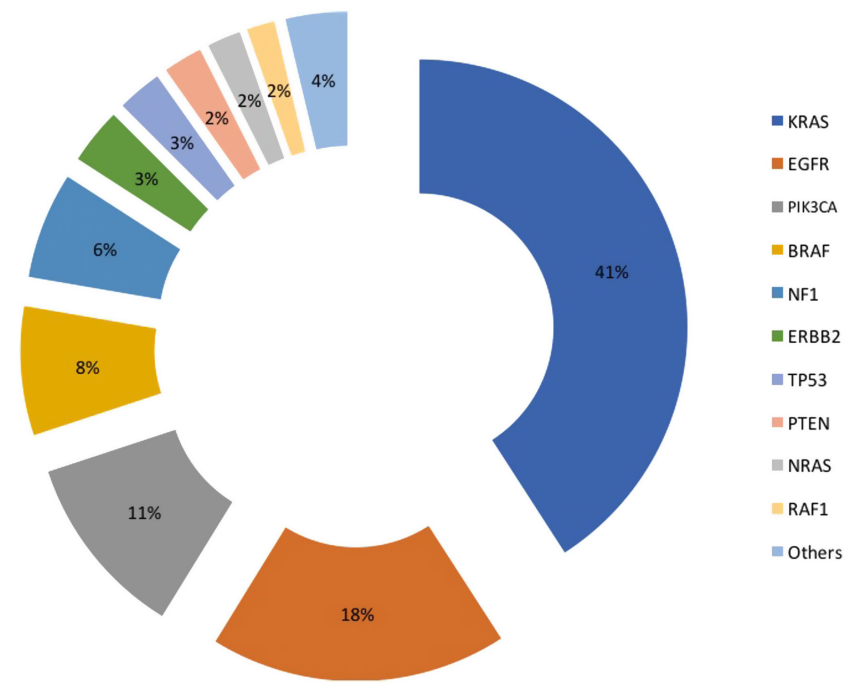

FIG. 2. Distribution of variants of strong significance detected in our study (others = ALK, ARID1A, CDKN2A, KIT, LRP1B, MGA, MUC16, PIK3R1, and SETD2).

(38.6\%), KRAS (20\%), PIK3CA (11.5\%), ERBB2 (8.6\%), and NF1 $(7.1 \%)$ were the most frequent in females. Males had a higher rate of $K R A S$ mutation $(P=.102)$, whereas $E G F R$ mutation was statistically more common in females $(P=.001$, Table 4$)$.

The 2 major histological subtypes of NSCLC in this study were adenocarcinoma (ADC) and squamous cell carcinoma (SCC). Kirsten rat sarcoma 2 viral oncogene homolog (44.3\%), EGFR (18.8\%), PIK3CA (8.5\%), BRAF (7.7\%), and NF1 (5.9\%) mutations were most frequently observed in ADCs. Phosphatidylino sitol-4,5-bisphosphate 3-kinase catalytic subunit alpha (40\%), NF1 (12\%), EGFR (8\%), BRAF (8\%), neuroblastoma RAS viral oncogene homolog (NRAS) (8\%), and tumor protein 53 (TP53) $(8 \%)$ mutations were most frequently observed in SCCs. Kirsten rat sarcoma 2 viral oncogene homolog $(P=.001)$ and $E G F R$ $(P=.040)$ mutations were more prevalent in ADC, and PIK3CA and NF 1 mutations were improved in SCC (Table 4). In the patients with adenosquamous carcinoma, VSS was not detected in either group. Of the 4 NSCLC cases without histological subtyping, KIT mutation was detected in 2 patients.

Among 302 patients with a smoking history, 242 (80.2\%) were diagnosed with ADC, 58 (19.2\%) with SCC, 1 (0.3\%) with adenosquamous carcinoma, and $1(0.3 \%)$ with NSCLC. Consideration of the relationship between histological subtypes and smoking status revealed that $82.3 \%(58 / 70)$ of SCC patients and $56.1 \%$ (242/431) of ADC patients had a smoking history. A total of 225 variants $(76 \%, 225 / 296)$ were detected in patients with smoking history. Variants of strong significance were most commonly observed in $\operatorname{KRAS}(50.2 \%, 113 / 225)$ followed by PIK3CA $(14.3 \%$, 32/225), BRAF (8.9\%, 20/225), EGFR (8.9\%, 20/225), NF1 (6.7\%, 15/225), TP53 (2.7\%, 6/225), NRAS (2.3\%, 5/225), PTEN $(2.3 \%, 5 / 225), \operatorname{LRP} 1 B(0.9 \%, 2 / 225), \operatorname{KIT}(0.4 \%, 1 / 225)$, ARIDIA (0.4\%, 1/225), ERBB2 (0.4\%, 1/225), CDKN2A (0.4\%, 1/225), MUC1 (0.4\%, 1/225), PIK3R1 (0.4\%, 1/225), and SETD2 (0.4\%, 1/225). 
TABLE 3. Described Variants of Strong Significance From the Study Group

\begin{tabular}{|c|c|c|c|c|}
\hline Gene & Location & N (296) & cDNA Change (Respectively) & $\begin{array}{l}\text { Protein Change } \\
\text { (Respectively) }\end{array}$ \\
\hline \multirow[t]{11}{*}{ KRAS, $n=121$} & Exon 2 & 47 & c. $34 \mathrm{G}>\mathrm{T}$ & p.G12C \\
\hline & & 24 & c. $35 \mathrm{G}>\mathrm{T}$ & p.G12V \\
\hline & & 18 & c. $35 \mathrm{G}>\mathrm{A}$ & p.G12D \\
\hline & & 10 & c. $35 \mathrm{G}>\mathrm{C}$ & p.G12A \\
\hline & & 4 & c. $37 \mathrm{G}>\mathrm{T}$ & p.G13C \\
\hline & & 3 & c. $38 \mathrm{G}>\mathrm{A}$ & p.G13D \\
\hline & & Each 1 & c.33_34delTGinsGT, c.34_35delGGinsTT, c.34G $>$ A, c.34G $>$ C, c.36T $>$ C, c.39C $>$ T & $\begin{array}{l}\text { p.G12C, p.G12F, p.G12S, } \\
\text { p G12R, p.G12G, p.G13G }\end{array}$ \\
\hline & Exon 3 & 3 & c. $183 \mathrm{~A}>\mathrm{T}$ & p.Q61H \\
\hline & & 2 & c. $183 \mathrm{~A}>\mathrm{C}$ & p.Q61H \\
\hline & Exon 4 & 3 & c. $437 \mathrm{C}>\mathrm{T}$ & p.A146V \\
\hline & & 1 & c. $436 \mathrm{G}>\mathrm{A}$ & p.A146T \\
\hline \multirow[t]{13}{*}{ EGFR, $n=53$} & Exon 7 & 1 & c. $866 \mathrm{C}>\mathrm{T}$ & p.A289V \\
\hline & Exon 18 & Each 1 & c. $2155 \mathrm{G}>\mathrm{A}, \mathrm{c} .2156 \mathrm{G}>\mathrm{C}$ & p.G719S, p.G719A \\
\hline & Exon 19 & 15 & c.2235_2249delGGAATTAAGAGAAGC & p.E746_750delEL \\
\hline & & 5 & c.2237_2255delAATTAAGAGAAGCAACATCinsT & p.E746_S752delinsV \\
\hline & & 3 & c.2239_2247delTTAAGAGAA & p.L747_E749del \\
\hline & & Each 2 & $\begin{array}{l}\text { c. } 2236 \_2250 \text { delGAATTAAGAGAAGCA, c.2240_2254delTAAGAGAAGCAACAT, } \\
\text { c. } 2248 \mathrm{G}>\mathrm{C}\end{array}$ & $\begin{array}{l}\text { p.E746_A750del, p.L747_ } \\
\text { T751del, p.750P }\end{array}$ \\
\hline & & Each 1 & 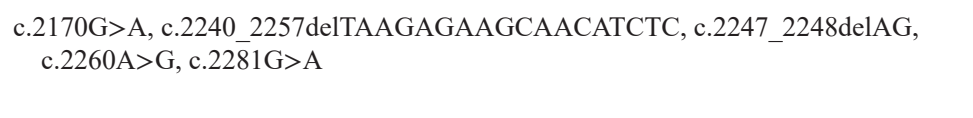 & $\begin{array}{l}\text { p.G724S, p.L747_- } \\
\text { P753delinsS, p.A750P, } \\
\text { p K754E, p.D761N }\end{array}$ \\
\hline & Exon 20 & 2 & c.2311_2319dupAACCCCCAC & p.N771_H773dup \\
\hline & & Each 1 & c.2300_2308dupCCAGCGTGG, c.2320G >A & p.A767_V769dup, p.V774M \\
\hline & Exon 21 & 5 & c. $2573 \mathrm{~T}>\mathrm{G}$ & p.L858R \\
\hline & & 4 & c. $2582 \mathrm{~T}>\mathrm{A}$ & p.L861Q \\
\hline & & 2 & c. $2543 \mathrm{C}>\mathrm{T}$ & p.P848L \\
\hline & & 1 & c.2573_2574delTGinsGA & p.L858R \\
\hline \multirow[t]{8}{*}{ PIK 3 CA, $n=33$} & Exon 2 & Each 1 & c. $113 \mathrm{G}>\mathrm{A}, \mathrm{c} .331 \mathrm{~A}>\mathrm{G}$ & p.R38H, p.K111E \\
\hline & Exon 8 & 2 & c. $1357 \mathrm{G}>\mathrm{C}$ & p.E453Q \\
\hline & & 1 & c. $1258 \mathrm{~T}>\mathrm{C}$ & p.C420R \\
\hline & Exon 10 & 13 & c. $1633 \mathrm{G}>\mathrm{A}$ & p.E545K \\
\hline & & Each 1 & c. $1624 \mathrm{G}>\mathrm{A}$, c. $1634 \mathrm{~A}>\mathrm{C}$, c $1637 \mathrm{~A}>\mathrm{G}, \mathrm{c} .1638 \mathrm{G}>\mathrm{C}$ & $\begin{array}{l}\text { p.E542K, p.E545A, p.Q546R, } \\
\text { p Q546H }\end{array}$ \\
\hline & Exon 21 & 6 & c. $3140 \mathrm{~A}>\mathrm{G}$ & p.H1047R \\
\hline & & 3 & c. $3140 \mathrm{~A}>\mathrm{T}$ & p.H1047L \\
\hline & & Each 1 & c. $3073 \mathrm{~A}>\mathrm{G}$, c. $3155 \mathrm{C}>\mathrm{A}$ & p.T1025A, p.T1052K \\
\hline \multirow[t]{5}{*}{ BRAF, $\mathrm{n}=23$} & Exon 11 & Each 2 & c. $1391 \mathrm{G}>\mathrm{T}, \mathrm{c} .1405 \mathrm{G}>\mathrm{C}$, c. $1406 \mathrm{G}>\mathrm{T}$ & p.G464V, p.G469R, p.G469V \\
\hline & & Each 1 & c. $1396 \mathrm{G}>\mathrm{A}$, c. $1405 \mathrm{G}>\mathrm{A}$, c $1406 \mathrm{G}>\mathrm{C}$ & p.G466R, p.G469R, p.G469A \\
\hline & Exon 15 & 9 & c. $1799 \mathrm{~T}>\mathrm{A}$ & p.V600E \\
\hline & & 2 & c. $1801 \mathrm{~A}>\mathrm{G}$ & p.K601E \\
\hline & & Each 1 & c. $1742 \mathrm{~A}>\mathrm{T}, \mathrm{c} .1742 \mathrm{~A}>\mathrm{G}, \mathrm{c} .1790 \mathrm{~T}>\mathrm{G}$ & p.N581I, p.N581S, p.L597R \\
\hline
\end{tabular}




\begin{tabular}{|c|c|c|c|c|}
\hline Gene & Location & N (296) & cDNA Change (Respectively) & $\begin{array}{l}\text { Protein Change } \\
\text { (Respectively) }\end{array}$ \\
\hline \multirow[t]{6}{*}{$\mathrm{NF} 1, \mathrm{n}=19$} & Exon 18 & 1 & c.2033dupC & p.I679fs $* 21$ \\
\hline & Exon 19 & 8 & c. $2325+3 \mathrm{~A}>\mathrm{G}$ & - \\
\hline & Exon 20 & 7 & c. $2392 \mathrm{~A}>\mathrm{C}$ & p.K798Q \\
\hline & Exon 28 & 1 & c. $3814 \mathrm{C}>\mathrm{T}$ & p.Q1272* \\
\hline & Exon 36 & 1 & c. $5170 \mathrm{~A}>\mathrm{T}$ & p.K1724* \\
\hline & Exon 42 & 1 & c.6522_6523delGA & p.E2174fs*46 \\
\hline \multirow[t]{4}{*}{$\mathrm{ERBB} 2, \mathrm{n}=10$} & Exon 8 & 1 & c. $929 \mathrm{C}>\mathrm{A}$ & p.S310Y \\
\hline & Exon 19 & 1 & c. $2305 \mathrm{G}>\mathrm{T}$ & p.D769Y \\
\hline & Exon 20 & 7 & c.2313_2324dupATACGTGATGGC & p.Y772_A775dup \\
\hline & & 1 & c.2312_2313insCTACGTGATGGC & p.Y772_A775dup \\
\hline \multirow[t]{5}{*}{$\mathrm{TP} 53, \mathrm{n}=7$} & Exon 4 & 1 & c. $313 \mathrm{G}>\mathrm{T}$ & p.G105C \\
\hline & Exon 5 & 1 & c. $469 \mathrm{G}>\mathrm{T}$ & p.V157F \\
\hline & Exon 7 & 1 & c. $742 \mathrm{C}>\mathrm{T}$ & p.R246W \\
\hline & Exon 8 & Each 1 & c. $817 \mathrm{C}>\mathrm{T}$, c $.817 \mathrm{C}>\mathrm{G}, \mathrm{c} .823 \mathrm{~T}>\mathrm{C}, \mathrm{c} .833 \mathrm{C}>\mathrm{A}$ & $\begin{array}{l}\text { p.R273C, p.R273G, p.C275R, } \\
\text { p P278H }\end{array}$ \\
\hline & Exon 9 & 1 & c. $961 \mathrm{~A}>\mathrm{T}$ & p.K321* \\
\hline PTEN & Exon 6 & 7 & c. $407 \mathrm{G}>\mathrm{A}$ & p.C136Y \\
\hline \multirow[t]{3}{*}{ NRAS, $\mathrm{n}=6$} & Exon 3 & 3 & c. $182 \mathrm{~A}>\mathrm{T}$ & p.Q61L \\
\hline & & 2 & c. $181 \mathrm{C}>\mathrm{A}$ & p.Q61K \\
\hline & & 1 & c. $182 \mathrm{~A}>\mathrm{G}$ & p.Q61R \\
\hline \multirow[t]{2}{*}{$\mathrm{RAF} 1, \mathrm{n}=5$} & Exon 7 & 3 & c. $770 \mathrm{C}>\mathrm{T}$ & p.S257L \\
\hline & & 2 & c. $776 \mathrm{C}>\mathrm{T}$ & p.S259F \\
\hline \multirow[t]{2}{*}{ LRP1B, $n=2$} & Exon 42 & 1 & c. $6852 \mathrm{C}>\mathrm{A}$ & p.Y2284* \\
\hline & Exon 50 & 1 & c. $8103 \mathrm{C}>\mathrm{A}$ & p.C2701* \\
\hline KIT & Exon 11 & 2 & c. $1676 \mathrm{~T}>\mathrm{A}$ & p.V559D \\
\hline ALK & Exon 25 & 1 & c. $3824 \mathrm{G}>\mathrm{A}$ & p.R1275Q \\
\hline ARID1A & Exon 18 & 1 & c. $4495 \mathrm{C}>\mathrm{T}$ & p.Q1499* \\
\hline CDKN2A & Exon 2 & 1 & c. $457+2 \mathrm{~T}>\mathrm{G}$ & - \\
\hline MGA & Exon 10 & 1 & c. $3463 \mathrm{C}>\mathrm{T}$ & p.R1155* \\
\hline MUC16 & Exon 3 & 1 & c. $22517 \mathrm{C}>\mathrm{A}$ & p.S7506* \\
\hline PIK3R1 & Exon 11 & 1 & c. $1312 \mathrm{~A}>\mathrm{T}$ & p.K438* \\
\hline SETD2 & Exon 14 & 1 & c.6190_6191delGA & p.D2064fs*8 \\
\hline
\end{tabular}

*Positions which have a single, fully conserved residue.

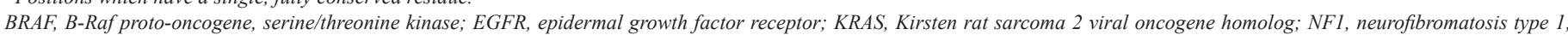
NRAS, neuroblastoma RAS viral oncogene homolog; PIK3CA, phosphatidylinositol-4,5-bisphosphate 3-kinase catalytic subunit alpha; TP53, tumor protein 53.

\section{Coexistence of Variants of Strong Significance in Non-small Cell Lung Cancer}

Among the 507 patients analyzed, 219 (43.1\%) had a minimum of 1 genomic mutation classified as VSS. There were 23 two-gene mutations, 7 three-gene mutations, and 2 five-gene mutations. Mutations were present in more than 1 gene in 32 patients $(6.3 \%$, 32/507). The most common concomitant mutations were KRAS and PIK3CA $(\mathrm{n}=10)$. Considering the distribution of concomitant VSS by tumor type, 30/32 cases were diagnosed with ADC, and only 2 cases were diagnosed with SCC. Among the 32 patients with concomitant mutations, $30(93.7 \%)$ had a history of smoking.
The most common concomitant VSS seen in smoking patients was KRAS-PIK3CA $(\mathrm{n}=10), K R A S-B R A F(\mathrm{n}=3), B R A F-P I K 3 C A$ $(\mathrm{n}=3), K R A S-N F 1(\mathrm{n}=2)$, and $K R A S-E G F R(\mathrm{n}=2)$. Details of the coexistence of VSS are summarized in Table 5.

\section{DISCUSSION}

Characterized by complex genomic alterations, lung cancer often presents as a solid tumor, which can be successfully treated using targeted therapies. ${ }^{3,5}$ Differences can be observed in lung cancer patients with similar clinical and histopathological features in prognosis and response to treatment. Therefore, molecular tests 
TABLE 4. Association of Patient Clinicopathological Characteristics with Variants of Strong Significance

\begin{tabular}{|c|c|c|c|c|c|c|c|}
\hline \multirow[b]{2}{*}{ Gene } & \multicolumn{3}{|c|}{ Male } & \multicolumn{3}{|c|}{ Female } & \multirow[b]{2}{*}{ Total, N (\%) } \\
\hline & ADC, n (\%) & $\mathrm{SCC}, \mathrm{n}(\%)$ & N (\%) & ADC, n (\%) & $\mathrm{SCC}, \mathrm{n}(\%)$ & N (\%) & \\
\hline KRAS & $106(51.2)$ & $1(5.3)$ & $107(47.3)$ & $14(21.9)$ & - & $14(20)$ & $121(41)$ \\
\hline EGFR & 24 (11.5) & $2(10.5)$ & $26(11.5)$ & $27(42.1)$ & - & 27 (38.6) & $53(18)$ \\
\hline PIK3CA & $18(8.7)$ & 7 (36.7) & $25(11.1)$ & $5(7.8)$ & $3(49.9)$ & $8(11.5)$ & $33(11)$ \\
\hline BRAF & $18(8.7)$ & $1(5.3)$ & $19(8.4)$ & $3(4.7)$ & $1(16.7)$ & $4(5.7)$ & $23(8)$ \\
\hline NF1 & $12(5.8)$ & $2(10.5)$ & $14(6.2)$ & $4(6.2)$ & $1(16.7)$ & $5(7.1)$ & $19(6)$ \\
\hline ERBB2 & $4(1.9)$ & - & $4(1.8)$ & $6(9.4)$ & - & $6(8.6)$ & $10(3)$ \\
\hline TP53 & $5(2.4)$ & $2(10.5)$ & $7(3.1)$ & $1(1.6)$ & - & $1(1.4)$ & $8(2.7)$ \\
\hline PTEN & $5(2.4)$ & - & $5(2.3)$ & $2(3.1)$ & - & $2(2.9)$ & $7(2.4)$ \\
\hline NRAS & $4(1.9)$ & $1(5.3)$ & $5(2.3)$ & - & $1(16.7)$ & $1(1.4)$ & $6(2)$ \\
\hline RAF1 & $3(1.5)$ & $1(5.3)$ & $4(1.8)$ & $1(1.6)$ & - & $1(1.4)$ & $5(1.7)$ \\
\hline LRP1B & $2(1)$ & - & $2(0.9)$ & - & - & - & $2(0.7)$ \\
\hline KIT & $2(1)$ & - & $2(0.9)$ & - & - & - & $2(0.7)$ \\
\hline ALK & $1(0.5)$ & - & $1(0.4)$ & - & - & - & $1(0.4)$ \\
\hline ARID1A & $1(0.5)$ & - & $1(0.4)$ & - & - & - & $1(0.4)$ \\
\hline CDKN2A & - & $1(5.3)$ & $1(0.4)$ & - & - & - & $1(0.4)$ \\
\hline MGA & - & - & - & $1(1.6)$ & - & $1(1.4)$ & $1(0.4)$ \\
\hline MUC16 & $1(0.5)$ & - & $1(0.4)$ & - & - & - & $1(0.4)$ \\
\hline PIK3R1 & - & $1(5.3)$ & $1(0.4)$ & - & - & - & $1(0.4)$ \\
\hline SETD2 & $1(0.5)$ & - & $1(0.4)$ & - & - & - & $1(0.4)$ \\
\hline Total N (\%) & $207(100)$ & $19(100)$ & $226(100)$ & $64(100)$ & $6(100)$ & 70 (100) & $296(100)$ \\
\hline
\end{tabular}

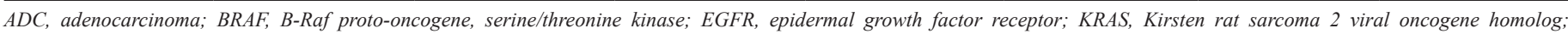

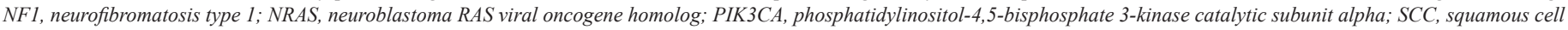
carcinoma.

have become more important for administering the most appropriate treatment for each patient. ${ }^{3,19}$ At present, tumor samples are used for diagnostic and molecular tests. ${ }^{2}$ According to the recently updated National Comprehensive Cancer Network guidelines for NSCLC, molecular testing is recommended as a routine for 9 genes: ALK, ROS1, EGFR, KRAS/NRAS, BRAF, RET, MET, ERBB2, and $P D L-1 .{ }^{23}$ However, chemotherapy is the only available treatment for patients who do not have any of these mutations. ${ }^{23,24}$ Therefore, instead of looking at certain mutations, characterizing as much of the tumor's gene profile as possible would be more effective against lung cancer in understanding the pathogenesis and determining the treatment. In cases of NSCLC, diagnosis is largely based on limited tumor tissue samples, and use of the same tissue samples for both diagnosis and molecular tests necessitates the transition to multiple gene panels or NGS methods, where all exons can be studied. ${ }^{2}$

In lung cancer, mutations may be associated with sex. ${ }^{4}$ In previous studies, sex-specific mutation profiles were detected in the tumor, and mutation profiles were associated with clinical results. It is believed that main cause of the differences in mutation profiles is primarily based on hormonal differences. ${ }^{15}$ Epidermal growth factor receptor mutations are more common in females; therefore, female patients with this mutation benefit more from $E G R F$ inhibitors. ${ }^{4,15}$ Similarly, the EGFR mutation was found more frequently in females in this study $(P=.001)$. In addition to genetic factors, many personal and environmental factors can influence the development of lung cancer. Among them, smoking is one of the most important factor. ${ }^{4,5}$ According to the literature, the smoking rate was higher in male patients. ${ }^{1,5,8}$ The results of this study are similar to those in the literature. ${ }^{15,19}$ In patients with a history of smoking, the most frequently cited mutations in the literature are $K R A S, P I K 3 C A, B R A F$, and $M E K 1 .^{1,3,5}$ In this study, the most frequent mutations in patients with a history of smoking were $K R A S, P I K 3 C A$, and BRAF which is consistent with the literature.

Adenocarcinoma and SCC are the 2 main histological subtypes of NSCLC. They have different genomic changes and clinical responses. ${ }^{1,5}$ Therefore, it is important to understand the carcinogenic mechanism of ADC and SCC to provide more effective therapeutic strategies. $^{24,25}$ Genetic mutations often occur in EGFR, KRAS, TP53, $C D K N 2 A$, and $N F 1$ in patients with lung ADC. ${ }^{3,5,12,23,26} P I K 3 C A$, TP53, NF1, CDKN2A, and SOX2 mutations are also frequently detected in SCC patients. ${ }^{5,12,27}$ In this study, the most common VSS were compatible with the underlying histopathology. Kirsten rat sarcoma 2 viral oncogene homolog $(P=.001)$ and EGFR $(P=.040)$ mutations were more common in ADC, whereas PIK3CA and NF1 mutations were more common in SCC. Although such correlations were previously reported for each gene, ${ }^{5,27}$ this study presents the molecular profile in patients with SCC and ADC. Thus, this study is the first to present the histopathological subtype relationship of NGS with many genes in NSCLC patients in a Turkish population. 
TABLE 5. Association of Patient Clinicopathological Characteristics with Coexistence of Variants of Strong Significance

\begin{tabular}{|c|c|c|c|c|c|c|c|c|}
\hline \multirow{2}{*}{$\begin{array}{l}\text { Gene Mutation } \\
\text { Numbers }\end{array}$} & \multirow[b]{2}{*}{ Variants } & \multicolumn{3}{|c|}{ Adenocarcinoma } & \multicolumn{3}{|c|}{ Squamous Cell Carcinoma } & \multirow[b]{2}{*}{ Total } \\
\hline & & Male, $\mathrm{n}$ & Female, $\mathrm{n}$ & $\mathrm{N}$ & Male, $n$ & Female, $n$ & $\mathrm{~N}$ & \\
\hline \multirow[t]{11}{*}{ Two gene mutations } & KRAS + EGFR & 1 & 1 & 2 & - & - & - & 2 \\
\hline & KRAS + BRAF & 2 & - & 2 & - & - & - & 2 \\
\hline & $\mathrm{KRAS}+\mathrm{NF} 1$ & 2 & - & 2 & - & - & - & 2 \\
\hline & KRAS + PIK3CA & 7 & 1 & 8 & - & - & - & 8 \\
\hline & KRAS + ERBB2 & 1 & - & 1 & - & - & - & 1 \\
\hline & $\mathrm{EGFR}+\mathrm{PIK} 3 \mathrm{CA}$ & - & 1 & 1 & - & - & - & 1 \\
\hline & $\mathrm{BRAF}+\mathrm{PIK} 3 \mathrm{CA}$ & 1 & - & 1 & - & 1 & 1 & 2 \\
\hline & $\mathrm{BRAF}+\mathrm{NRAS}$ & 1 & - & 1 & - & - & - & 1 \\
\hline & $\mathrm{NF} 1+\mathrm{PTEN}$ & - & 1 & 1 & - & - & - & 1 \\
\hline & $\mathrm{NF} 1+\mathrm{TP} 53$ & 2 & - & 2 & - & - & - & 2 \\
\hline & PTEN, MUC16 & 1 & - & 1 & - & - & - & 1 \\
\hline \multirow[t]{6}{*}{ Three gene mutations } & $\mathrm{KRAS}+\mathrm{PIK} 3 \mathrm{CA}+\mathrm{BRAF}$ & 1 & - & 1 & - & - & - & 1 \\
\hline & $\mathrm{EGFR}+\mathrm{ERBB} 2+\mathrm{ALK}$ & 1 & - & 1 & - & - & - & 1 \\
\hline & KRAS + TP53+SETD2 & 1 & - & 1 & - & - & - & 1 \\
\hline & $\mathrm{PIK} 3 \mathrm{CA}+\mathrm{KRAS}+\mathrm{KIT}$ & 1 & - & 1 & - & - & - & 1 \\
\hline & $\mathrm{EGFR}+\mathrm{NF} 1+\mathrm{PTEN}$ & 1 & 1 & 2 & - & - & - & 2 \\
\hline & $\mathrm{KRAS}+\mathrm{NF} 1+\mathrm{PTEN}$ & 1 & - & 1 & - & - & - & 1 \\
\hline \multirow[t]{2}{*}{ Five gene mutations } & NF1 + ARID1A+PTEN+TP53 + LRP1B & 1 & - & 1 & - & - & - & 1 \\
\hline & $\mathrm{EGFR}+\mathrm{PIK} 3 \mathrm{R} 1+\mathrm{TP} 53+\mathrm{CDKN} 2 \mathrm{~A}+\mathrm{NF} 1$ & - & - & - & 1 & - & 1 & 1 \\
\hline Total & & 25 & 5 & 30 & 1 & 1 & 2 & 32 \\
\hline
\end{tabular}

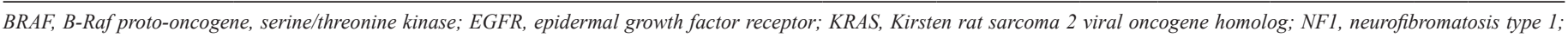
NRAS, neuroblastoma RAS viral oncogene homolog; PIK3CA, phosphatidylinositol-4,5-bisphosphate 3-kinase catalytic subunit alpha.

The frequency of mutations detected in patients with NSCLC differs according to geographical location and especially ethnicity. Kirsten rat sarcoma 2 viral oncogene homolog and EGFR are the most frequently tested mutations in patients with NSCLC. ${ }^{12,17}$ Kirsten rat sarcoma 2 viral oncogene homolog mutation has been associated with poor prognosis and resistance to therapy. ${ }^{2,5}$ Kirsten rat sarcoma 2 viral oncogene homolog is more common in Western countries (20-40\%), in the United States (15-35\%) and has been observed at lower rates (10-14\%) in Asian countries. ${ }^{12,17}$ In a single-centered study in Turkey, it was reported to be $35.4 \% .{ }^{28}$ In previous studies, $K R A S$ mutations were frequently localized in exons 2 and 3 occurring in codon 12 as a $70 \%$ guanine-thymine transversion. ${ }^{3,19}$ In this study, the percentage of KRAS mutations was similar to that of the Western countries, being $41 \%$. Similar to the literature, mutations were most frequently localized in exon 2 (92.5\%), with the vast majority $(85.9 \%)$ detected in codon 12 . In contrast to the KRAS mutation, the EGFR mutation is more common in Asian countries (20-30\%) with 2-14\% in Western countries, $10-15 \%$ in the United States, and $16.7 \%$ in Turkey. ${ }^{5,9,12,21}$ The most frequent mutations are localized in exons 19 and $21 .^{3,5,19}$ In this study, the EGFR mutation rate was $18 \%$. In accordance with previous reports, the majority of EGFR mutations were found in exons 19 (64\%) and $21(22.6 \%)$, and these mutations are associated with increased sensitivity to tyrosine kinase inhibitors in patients ${ }^{5}$ (Table 6).

Phosphatidylinositol-4,5-bisphosphate 3-kinase catalytic subunit alpha is a potential therapeutic protein, and there are ongoing studies regarding the development of new drugs against the activity of

TABLE 6. Comparison of the Most Frequently Detected Mutations With International and National Literature

\begin{tabular}{|c|c|c|c|c|c|}
\hline \multirow[b]{2}{*}{ Mutations } & \multicolumn{3}{|c|}{ International Literature (\%) } & \multicolumn{2}{|c|}{ National Literature (\%) } \\
\hline & Western Countries & Asian Countries & United States & Previous Studies & Present Study \\
\hline KRAS & $20-40$ & $10-14$ & $15-35$ & 35.4 & 41 \\
\hline EGFR & $2-14$ & $20-30$ & $10-15$ & 16.7 & 18 \\
\hline PIK3CA & $1-4$ & $1-4$ & $1-4$ & 7.5 & $11^{\mathrm{a}}$ \\
\hline BRAF & $2-4$ & $0.8-2$ & $2-4$ & - & $8^{\mathrm{a}}$ \\
\hline NF1 & $1-5$ & $1-5$ & $1-5$ & - & $6^{\mathrm{a}}$ \\
\hline
\end{tabular}

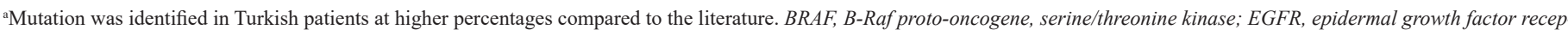

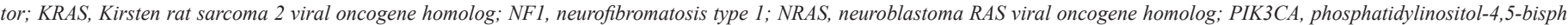
osphate 3-kinase catalytic subunit alpha. 
$P I K 3 C A .^{3,20}$ In the literature, the frequency of $P I K 3 C A$ mutation in NSCLC is reportedly $1-4 \% .{ }^{15,17}$ In a study in Turkey, the frequency of $P I K 3 C A$ gene mutation was determined to be $7.5 \%,{ }^{20}$ which was $11 \%$ (Table 6). The most common VSS was found in exon 10 $(51.5 \%)$ followed by exon $21(33.5 \%)$. Studies have shown that these variants can be considered oncogenic and targeted for drug development. ${ }^{3,5}$ This study demonstrated that PIK3CA mutations were more frequent in Turkish patients with NSCLC. This may be due to the patients or differences between the countries. It is predicted that the development of successful PIK3CA-targeted therapy will be vital for a significant number of NSCLC patients in Turkey.

The frequency of BRAF is about $2-4 \%$ in Western countries and patients from the United States and as $0.8-2 \%$ in Asian countries. ${ }^{2,12}$ It is most frequently observed in the form of the V600E point mutation in NSCLC cases. ${ }^{3,12,19,23}$ In this study, the BRAF mutation was detected at a higher rate compared to the literature and observed in $8 \%$ of VSS cases (Table 6). p.V600E represented $39.1 \%$ of $B R A F$ mutations. Evaluation of the BRAF V600E mutation may be important for targeted therapies because it plays a role in intracellular signaling when activated. ${ }^{19}$

Mutations in the NF1 have also been observed in lung cancer cases; however, the clinical significance and molecular characterization are not yet fully clarified. The link between NF1 and RAS signals suggests that NF1 mutations may have great clinical significance in lung cancer. In the literature, the NF1 mutation in NSCLC was found to be $1-5 \% .{ }^{26}$ In this study, it was detected in $6 \%$ of VSS cases (Table 6). Further studies on patients with NF1 mutations may reveal a different group of tumors other than $K R A S$ mutant lung cancers that can be used for a therapeutic targets associated with the RAS pathway. ${ }^{24}$

Targeted drugs for the treatment of NSCLC have been growing and improving. ${ }^{18}$ However, there is often no response or different responses to the treatment administered to patients with similar mutations. ${ }^{14,16}$ Therefore, additional indicators are needed to better predict the response to treatment in such patients. In addition to the predetermined mutation, detection of further mutations can lead to a more effective treatment outcome. According to data obtained from the Lung Cancer Mutation Consortium, more than 1 VSS association can be observed in approximately $3 \%$ of cases with lung ADC. ${ }^{29}$ This rate appears to be relatively low. However, increasing evidence suggests that existing gene mutations may change the scope and duration of response to targeted agents. Multiple variants were found in $6.3 \%$ of patients included in this study. Approximately $90 \%$ of patients with multiple mutations were diagnosed with ADC, and 4/5 of them had a history of smoking. These results highlight that multiple gene panels should be studied instead of single-gene mutations, particularly in patients with ADC and a history of smoking.

The combination of VSS has been frequently discussed in the literature. Studies have demonstrated that $B R A F$ can coexist with $E G F R, K R A S, A L K$, and PTEN. ${ }^{5,12}$ The high frequency of concomitant $P I K 3 C A$ mutations has significant clinical implications for targeted therapy. ${ }^{5,11}$ In this study, KRAS-PIK3CA was the most common mutation observed. It is believed that these concomitant genomic alterations could be associated with cancer progression and acquired drug resistance rather than oncogenic driver alterations. Kirsten rat sarcoma 2 viral oncogene homolog, EGFR, $A L K$, and ROS1 mutations are considered to be mutually exclusive, with mutations that are unlikely to be in the same patient when one or the other is present.,12,18 However, this study reported 2 cases with coexisting EGFR (exons 19 and 21) and KRAS (codon 12) mutations. This study is a rare study demonstrating simultaneous mutations in driver genes in Turkish NSCLC patients, and it is thought that the number of reports will increase in Turkey. The detection of multiple oncogene mutations can be helpful in determining the optimal treatment protocol.

In conlusion, $P I K 3 C A, B R A F$, and $N F 1$ mutations were identified in Turkish patients at higher percentages than in the literature. Epidermal growth factor receptor mutation rates were also between those of Asian and Western countries. In this study, 6.3\% of patients had VSS together, most of whom were diagnosed ADC and were smokers. The most common concomitant mutations were $K R A S$ and $P I K 3 C A$. These results suggest that these mutations should be considered more in diagnosis and treatment, thereby contributing to treatment success. It also emphasizes that multiple gene panels should be studied instead of single-gene mutation panels, particularly in patients with ADC and smoking history. Further studies on determining genetic alterations specific to Turkey, understanding their rates, and demonstrating their correlations will help guide the clinicians in the treatment and significantly contribute to determining diagnostic priorities.

Ethics Committee Approval: Ethics committee approval was received for this study from the Ethics Committee of Aydın Adnan Menderes University School of Medicine, Aydın, Turkey by the approval number 22/2020.

Patient Consent for Publication: N/A.

Data-sharing Statement: The data that support the findings of this study are available from the corresponding author upon reasonable request.

Author Contributions: Concept - N.K.C; Design - N.K.C., I.H.E.; Supervision - N.K.C., İ.H.E, İ.M.; Materials - N.K.C., İ.H.E., E.B.; Data Collection and/or Processing - N.K.C., E.B.; Analysis and/or Interpretation - E.B., N.K.C.; Literature Review - N.K.C., E.B., İ.M.; Writing - N.K.C; Critical Review - İ.H.E., I.M.

Conflict of Interest: The authors have no conflicts of interest to declare.

Funding: The authors declared that this study had received no financial support.

\section{REFERENCES}

1. Travis WD, Brambilla E, Burke AP, Marx A, Nicholson AG, FRCPath. WHO Classification of Tumours of the Lung, Pleura, Thymus and Heart. Lyon, France: International Agency for Research on Cancer (IARC); 2015:11-112.

2. Öz B. Targeted treatments in lung cancer. Toraks Cerrahisi Bul. 2017;10:39-44.

3. Bozkurtlar E, Kaya H. Molecular pathology of lung cancer. Nucl Med Semin. 2018;4(1):26-31. [CrossRef]

4. Gridelli C, Rossi A, Carbone DP, et al. Non-small-cell lung cancer. Nat Rev Dis Primers. 2015;1:15009. [CrossRef] 
5. Jiang R, Zhang B, Teng X, et al. Validating a targeted next-generation sequencing assay and profiling somatic variants in Chinese non-small-cell lung cancer patients. Sci Rep. 2020;10(1):2070. [CrossRef]

6. Siegel RL, Miller KD, Jemal A. Cancer statistics, 2016. CA Cancer J Clin. 2016;66(1):7-30. [CrossRef]

7. Cheng L, Zhang S, Alexander R, et al. The landscape of EGFR pathways and personalized management of non-small-cell lung cancer. Future Oncol. 2011;7(4):519541. [CrossRef]

8. Zhang Y, Shen WX, Zhou LN, et al. The value of next-generation sequencing for treatment in non-small-cell lung cancer patients: the observational, real-world evidence in China. BioMed Res Int. 2020;2020:9387167. [CrossRef]

9. Mayo-de-Las-Casas C, Jordana-Ariza N, Garzón-Ibañez M, et al. Large scale, prospective screening of EGFR mutations in the blood of advanced NSCLC patients to guide treatment decisions. Ann Oncol. 2017;28(9):2248-2255. [CrossRef]

10. Kerr KM, Bubendorf L, Edelman MJ, et al. Second ESMO consensus conference on lung cancer: pathology and molecular biomarkers for non-small-cell lung cancer. Ann Oncol. 2014;25(9):1681-1690. [CrossRef]

11. Hagemann IS, Devarakonda S, Lockwood CM, et al. Clinical next-generation sequencing in patients with non-small-cell lung cancer. Cancer. 2015;121(4):631639. [CrossRef]

12. Gupta P, Saha K, Vinarkar S, et al. Next generation sequencing in lung cancer: an initial experience from India. Curr Probl Cancer. 2020;44(3):100562. [CrossRef]

13. Chennagiri N, White EJ, Frieden A, et al. Orthogonal NGS for high throughput clinical diagnostics. Sci Rep. 2016;6:24650. [CrossRef]

14. Tan DSW, Mok TSK, Rebbeck TR. Cancer genomics: diversity and disparity across ethnicity and geography. J Clin Oncol. 2016;34(1):91-101. [CrossRef]

15. Ulas A, Tokluoglu S, Kos M, et al. Lung cancer in women, a different disease: survival differences by sex in Turkey. Asian Pac J Cancer Prev. 2015;16(2):815-822. [CrossRef]

16. Ma BB, Hui EP, Mok TS. Population based differences in treatment outcome following anti-cancer drug therapies. Lancet Oncol. 2010;11(1):75-84. [CrossRef]

17. Buyuksimsek M, Togun M, Oguz KI, et al. Results of liquid biopsy studies by next generation sequencing in patients with advanced stage non-small-cell lung cancer: single center experience from Turkey. Balkan J Med Genet. 2019;22(2):17-24. [CrossRef]
18. Erdoğdu Hİ. Next-generation sequencing (NGS): our results of molecular pathology malignant solid tumor panel. Int J Adv Res. 2019;7(1):306-311. [CrossRef]

19. Dogan M, Demirkazik A, Tukun A, et al. The relationship Between common EGFR, BRAF, KRAS mutations and prognosis in advanced stage non-small-cell lung cancer with response to the treatment in Turkey. Int J Hematol Oncol. 2014;24(1):1-10. [CrossRef]

20. Ekinci S, Ilgin-Ruhi H, Dogan M, et al. Molecular spectrum of PIK3CA gene mutations in patients with non-small-cell lung cancer in Turkey. Genet Test Mol Biomarkers. 2015;19(7):353-358. [CrossRef]

21. Güler Tezel GG, Şener E, Aydın Ç, Önder S. Prevalence of epidermal growth factor receptor mutations in patients with non-small cell lung cancer in Turkish population. Balkan Med J. 2017;34(6):567-571. [CrossRef]

22. Li MM, Datto M, Duncavage EJ, et al. Standards and guidelines for the interpretation and reporting of sequence variants in cancer: a joint consensus recommendation of the Association for Molecular Pathology, American Society of Clinical Oncology, and College of American Pathologists. J Mol Diagn. 2017;19(1):4-23. [CrossRef]

23. Iyer S, Prajapati R, Ramesh A, et al. The future of lung cancer therapy: striding Beyond conventional EGFR and ALK treatments. Mol Clin Oncol. 2019;10(4):469475. [CrossRef]

24. Oxnard GR, Binder A, Jänne PA. New targetable oncogenes in non-small-cell lung cancer. J Clin Oncol. 2013;31(8):1097-1104. [CrossRef]

25. Hamburg MA, Collins FS. The path to personalized medicine. $N$ Engl J Med. 2010;363(4):301-304. [CrossRef]

26. Redig AJ, Capelletti M, Dahlberg SE, et al. Clinical and molecular characteristics of NF1-mutant lung cancer. Clin Cancer Res. 2016;22(13):3148-3156. [CrossRef]

27. Lindeman NI, Cagle PT, Aisner DL, et al. Updated molecular testing guideline for the selection of lung cancer patients for treatment with targeted tyrosine kinase inhibitors: guideline from the college of American Pathologists, the International Association for the Study of Lung Cancer, and the Association for Molecular Pathology. Arch Pathol Lab Med. 2018;142(3):321-346. [CrossRef]

28. Basdemirci M, Zamani A, Zamani AG, Findik S, Yildirim MS. Extended-spectrum of KRAS and NRAS mutations in lung cancer tissue specimens obtained with bronchoscopy. Indian J Cancer. 2021:766-719. [CrossRef]

29. Sholl LM, Aisner DL, Varella-Garcia M, et al. Multi-institutional oncogenic driver mutation analysis in lung adenocarcinoma: the lung cancer mutation consortium experience. $J$ Thorac Oncol. 2015;10(5):768-777. [CrossRef] 